\title{
Using X-ray fluoresces analysis to assess level of major and trace elements in cultivated vegetables at Baghdad city
}

\author{
Mahdi M. Mutter \\ Ministry of science and technology Baghdad, Iraq \\ Email: mahdimutter@yahoo.com
}

Keywords: qualitative EXRFS-analysis, major elements, Trace element

\begin{abstract}
The aim of this study was determine the current levels of major and a trace element in vegetables was grown in Baghdad city, two region check in this study (Al-Taji, north of Baghdad and Al-Rashid south of Baghdad).Qualitative X-ray fluorescence analysis was used as technique for analysis of samples. Six different samples of plant are selected to study, which was tubers, leafy and fruiting .Samples checking was Lettuce, Bean, Apples, Potato, Cabbage and pear. Elements analysis as major elements were ( $\mathrm{Ca}, \mathrm{K}$ and $\mathrm{Mn}$ ) and trace elements were ( $\mathrm{Fe}, \mathrm{Cu}, \mathrm{Pb}, \mathrm{Sr}$ and $\mathrm{Zn})$. Results showed that concentrations of elements are in relative agree with the concentrations in neighbor countries and the standards of IAEU.
\end{abstract}

\section{INTRODUCTION}

My country, Iraq has witnessed during the last two decades, two wars. The two wars was very dangerous in which prohibited weapons were used. The international prohibited weapons had led to destruction of the infrastructures of environment. So there was an inner pollution which need to be monitored as well as the movement of elements in soil. This is most needed in the industrial areas and near energies facilities. Thus we regularly make research to monitor the pollution in the environment.

In the last few decades, the measurement of minerals and trace elements is important to enhance production efficiency in plants and foods [1]. The different elements are moving to the food chain of humans is affected by the geological origin of the soils and the ground waters basin as well as living area of the flora and the drinking water reservoirs. However, If the nutrients increased above the normal limit, it will increase the levels of cadmium and lead above essential requirements of these elements for human nutrition. On the other hand, the pollution have been considered environment effect on the concentration of elements in soil [2].

Many mineral elements are considered "trace" quantities as $(\mathrm{C}, \mathrm{H}, \mathrm{O}, \mathrm{N}, \mathrm{P}, \mathrm{S}, \mathrm{Ca}, \mathrm{Zn}, \mathrm{B}, \mathrm{Fe}$, $\mathrm{Mo}, \mathrm{Cl}, \mathrm{Mn}$ and $\mathrm{Ni}$ ) are essential for plant life [3] where for human 25 elements by increasing (Na, F, Si, V, Cr, Co, Se, Sn, and I) are considered essential [4], in addition and elements, Al and Li, have been included as possibly essential $[5,6]$. The 25 essential elements are $(\mathrm{Na}, \mathrm{K}, \mathrm{Mg}, \mathrm{Ca}, \mathrm{Cv}$, $\mathrm{Mm}, \mathrm{Fe}, \mathrm{Co}, \mathrm{Ni}, \mathrm{Cu}, \mathrm{Zn}, \mathrm{Se}, \mathrm{Mo}$ and $\mathrm{Sn})$. Just as some major (Ca, $\mathrm{K}$ and $\mathrm{Mg}$ ) and a trace elements (other elements).

Number of studies have been carried out in many countries due to investigate the levels of trace elements and major in plant, (D. Yilds et al, 2010) [7] study the level of a trace element in twenty nine samples collected from Bozday mountain of Aegeam region in turkey he found concentration from (0.02-5.983) Mg.g $\mathrm{g}^{-1}$ for some a trace elements. (S.M. Al-Jobori, et al, 1990) [8] in Iraq study's achieved about elements of rice are found normal. The techniques most widely used for analyses of various plants include ICP-OEs (Inductively coupled plasma optical emission spectrometry), ICPMs (In-addictively coupled plasma mass spectrometry), FAAS (Flame atomic absorption spectrometry) and ETAAS (Electro thermal AAS) [1,2]. The EDXRFS (Energy-dispersive X-ray fluorescence) consider is important technique in this field [9]. In our research we used quantitative EXRF analysis technique. 
The goal of this study was to investigate the concentration of trace and major elements in vegetables, which is cultivated in Baghdad city as tuber, leafy and fruiting plants the period of the research was 2014-2015.

\section{EXPERIMENTAL DETAIL}

\section{2-1 Sample preparation}

Vegetable samples collected from two region in Baghdad, Iraq, (lettuce, bean, Apples) from Al-Taji region and (Potato, cabbage, pear) from Al-Rashed region, in addition samples of soil from each region, see table (1).

Table (1): Represents the samples choosing of vegetables and area of grow thing

\begin{tabular}{|l|l|l|}
\hline Type of plant & name & Area of grow thing \\
\hline \multirow{2}{*}{ Tubers } & Bean & Al- Taji \\
\cline { 2 - 3 } & Potato & Al- Rashid \\
\hline \multirow{2}{*}{ Leafy } & Lettuce & Al- Taji \\
\cline { 2 - 3 } & Cabbage & Al- Rashid \\
\hline fruiting & Apples & Al- Taji \\
\cline { 2 - 3 } & pear & Al- Rashid \\
\hline
\end{tabular}

Vegetables samples were cleaned with tap water, doubly distilled water and kept in oven at $85 \mathrm{C}^{\circ}$ until they are dry and then dried samples are milled to a fine homogeneous powder using an electric mortar, and then are prepared in pellet form by pressing using 15 tons over area of $3.2 \mathrm{~cm}$ to give pellets of thickness of $0.4 \mathrm{~cm}$ at weight 4 gram from each samples.

\section{2-2 Experimental system and data analysis}

The samples were excited with Cd-10, annular X-ray source of an activity of $10 \mathrm{MCI}$ emitting $22.1 \mathrm{Kev}$ primary photon. The elemental secondary x-rays were measured with $\mathrm{Si}(\mathrm{Li})$ detector (Canberra type) having resolution of $171 \mathrm{eV}$ for the $5.9 \mathrm{Kev} \mathrm{K \alpha}$. X-ray emitted by Fe-55 source. The measurements have been done with computerized MCA for 3000 seconds. Eight different elements namely $\mathrm{Ca}, \mathrm{K}, \mathrm{Fe}, \mathrm{Ca} \mathrm{Mn}, \mathrm{Pb}, \mathrm{Sr}$ and $\mathrm{Zn}$ were detected.

\section{RESULTS AND DISCUSSIONS}

The elemental concentration were qualitatively determined relative to standard reference material (Orchard leaves-1571). Table (2) presents the energies of X-ray emitted by determined elements and the detection limit for each vegetable type collected from different location of Baghdad. The average concentration of elements obtained is shown in tables $(, 3,4,5,6)$. Tables $(, 3)$ explained the major elements in all vegetables in our choice to study, which is calcium, potassium and iron. Tables $(4,5)$ indicate concentration of a trace element, which are copper, Manganese, Lead, Strontium and Zinc.

Table(2) Energy and detection limit for the elements determined

\begin{tabular}{|l|l|l|}
\hline Element & E X-ray Kev & Detection limit ppm \\
\hline $\mathrm{K}$ & 3.31 & $0.04 \%$ \\
\hline $\mathrm{Ca}$ & 3.96 & $0.10 \%$ \\
\hline $\mathrm{Fe}$ & 6.40 & 11.06 \\
\hline $\mathrm{Cu}$ & 8.04 & 2.20 \\
\hline $\mathrm{Zn}$ & 8.63 & 2.12 \\
\hline $\mathrm{Sr}$ & 14.16 & 7.75 \\
\hline
\end{tabular}


Table (3): Represented the concentration of major elements in choosing samples in (PPm) for Al-Taji area

\begin{tabular}{|l|l|l|l|}
\hline Samples & Ca & K & Fe \\
\hline Lettuce & $21129+10.32$ & $31412.16+25.2$ & $223.04+15.23$ \\
\hline Bean & $18421.1+15.21$ & $210.71+30.1$ & $253.19+35.2$ \\
\hline Apples & $10210.3+50.21$ & $9315.82+100.1$ & $327.51+21.3$ \\
\hline Soil & $1121.23+40.2$ & $540.37+10.1$ & - \\
\hline
\end{tabular}

The concentration of a major and a trace elements in Al-Taji area in table $(3,4)$ was for calcium concentration in the varies vegetables are choosing between (18421-1121) ppm and potassium was (9315.82-210.71) ppm and iron was $(327.51-223.04) \mathrm{ppm}$, as well as the a trace elements copper (43.5-3.607) ppm, Manganese (7.13-1.78) ppm Lead (7.64-0.3) ppm, strontium (40-0.63) ppm and zinc (38.57-21.54) ppm.

Table (4): Represented the concentration of major elements in choosing samples in (PPm) for

\begin{tabular}{|l|l|l|l|}
\hline Samples & Ca & K & Fe \\
\hline Potato & $945.68+30.1$ & $8352.2+90.4$ & $292.3+1.3$ \\
\hline Cabbage & $13147.23+70.2$ & $5410.6+50.4$ & $310.20+5.41$ \\
\hline Pear & $15617.41+60.5$ & $6733.41+75.2$ & $410.5+10.3$ \\
\hline Soil & $1268.86+67.3$ & $1477.52+30.55$ & - \\
\hline
\end{tabular}

Compared with previous studies [9. 7], iron and strontium is high relatively in composition, this is due to much used origin compost.

For Al-Rashid area the results shown in table $(5,6)$ for major and trace elements, calcium concentration (15627-945.68) ppm, potassium (6733.41-1477.52) ppm iron (410.5-292.3) ppm, copper (54.42-7.78) ppm, Manganese (2.1-1.21) ppm, Lead (2.1-0.23) ppm, strontium (10.36-0.12) ppm and Zinc (26.110-23.804) ppm. The high concentration for Lead, strontium and Zinc belong to factory of electricity and some of chemical factories in the region, but is not approaching harmless to human.

Table (5): Represented the concentration of a trace elements in choosing samples in (PPm) for Al-Taji area

\begin{tabular}{|l|l|l|l|l|l|}
\hline Samples & $\mathbf{C u}$ & $\mathbf{M n}$ & $\mathbf{P b}$ & $\mathbf{S r}$ & $\mathbf{Z n}$ \\
\hline Lettuce & $16.1+3.1$ & $1.76+0.01$ & $2.33+0.04$ & $20.14+5.0$ & $39.74+5.1$ \\
\hline Bean & $11.682+1.3$ & $5.87+0.05$ & $6.37+0.01$ & $40.03+6.1$ & $38.51+4.1$ \\
\hline Apples & $43.5+13.1$ & $7.13+0.02$ & $0.3+0.04$ & $3.2+0.1$ & $30.2+5.1$ \\
\hline Soil & $3.607+0.12$ & - & $7.611+0.02$ & $0.63+0.05$ & $21.45+5.2$ \\
\hline
\end{tabular}

Table (6): Represented the concentration of a trace elements in choosing samples in (PPm) for Al-Rashid area

\begin{tabular}{|l|l|l|l|l|l|}
\hline Samples & $\mathbf{C u}$ & $\mathbf{M n}$ & $\mathbf{P b}$ & $\mathbf{S r}$ & $\mathbf{Z n}$ \\
\hline Potato & $8.18+1.6$ & - & $2.01+0.01$ & $10.36+0.4$ & $\begin{array}{l}23.80+ \\
2.11\end{array}$ \\
\hline Cabbage & $13.3+4.1$ & $1.21+0.03$ & $0.23+0.05$ & $0.12+0.05$ & $30.21+3.2$ \\
\hline Pear & $54.42+6.3$ & $2.10+0.03$ & $2.1+0.03$ & $0.4+0.1$ & $45.31+4.1$ \\
\hline Soil & $7.78+1.5$ & - & $1.1+0.01$ & $8.44+0.4$ & $26.11+1.1$ \\
\hline
\end{tabular}

On the other hand, the results of soil showed there are some elements like iron and manganese didn't find. The plant can get it from matter and these results indicated there are relatively contamination in water in these area. 


\section{CONCLUSION}

Flowing the results obtained in the analysis of a trace and major elements of vegetables grow thing in Baghdad city showed:

1- The concentration of major elements for matter in Al- Taji area showed the calcium values (21129-10210)ppm, potassium (31412.16- 210.71)ppm and iron (327.51-223.04)ppm, while the concentration of copper(43.5-16.1)ppm, manganese (7.13-1.67)ppm,lead(1.1-0.23)ppm, strontium (10.36-0.12)ppm and zinc(45.31-23.8)ppm.

2- For matter of Al- Rashid area, the concentration of major elements were calcium (15617.41945.88)ppm, potassium(8352.2-5410.6)ppm and iron(410.5-292.3)ppm, while the concentration of copper(54.42-8.18)ppm, manganese (2.10-1.21)ppm, lead(2.1-0.23)ppm, strontium(10.36-0.4)ppm and zinc (45.31-30.21)ppm.

3- Elements like calcium, potassium, copper, strontium and zinc in the soil of Al- Rashid higher than Al Taji area, while lead in the Al- Taji area higher than Al -Rashid area.

4- Some of the trace elements are include iron, manganese, Zinc and copper are essential micronutrients with variety of biochemical function in all living organism. This concentration indicates to use a lot of from organ composite and condition safety of some factory is weak.

\section{RECOMMENDATION}

Research must be continued to analysis more samples and cover all type of vegetables with special regard for the type of soil.

\section{REFERENCE}

[1] L. H. Rodrigue, , A. D. Morales, E. R. Rodriguea, , Minerols and trace elements in a collection of wheat laudraces from the canary Islands. Jornul of food composition and Analysis, 24, 10811090 (2011).

[2] K. Korhmaz, , S. M. Kara, , F. Ozkutln, Monitoring of heavy metals and selected micronntrients in hempseed from north- western Tarke'. African Jounr. Of Agricultural Research, 5, 463-467 (2010).

[3] F. B. Salisbury and C. W. Ross," Plant Physiology". 4th Edition. Wadsworth Publishing Co.,Belmont, California, 1992, pp 260-261.

[4] M. Geldmacher-von Mallinckrodt and D. Meissner, "General spects of the rode of metals in clinical chemistry, in handbook on Metals in Clinical and Analytic chemistry, H. Cr. Seiler, A. sigel, and H. Sigel, eds., Marcel Dekker, New York, pp 13-29 (1994).

[5] F. H. Nielsen, Evolution any event culminating in specific mineral becoming essential for life, Eur. J. Nutr. 39(2), 62-66, (2000).

[6] G. N. Schrauzer, Lithium: occurrence, dietary intakes and nutritional essentiality, J. Am. Coll. Nurt. 21, 14-21 (2002).

[7] D. Yilds, I. Kula, G. A. Y., Buslar and Y. Dogan, determination of trace elements in the plants of MT. Bozdagg Izmir, Turkey, Arch. Biol. Sci, Belgrade, 63(3), 733-740, (2010).

[8] S. M. Al-Jobori K.M. Shihab, M. Talil, , Multielement determination in rice, wheat and barley by in strumental neutron activation analysis, Biol. Trace Element Res. 26-27, 637-645 (1990).

[9] S. M. Al-Jobori, R. K. Hwi, D. A. Twaij, Determination of major and trace elements in Iraq vegetable samples by XRF, Math. And Phy. Vol 16(3), (2001). 